\title{
Hyaluronic Acid as an Alternative to Autologous Human Serum Eye Drops: Initial Clinical Results with High-Molecular-Weight Hyaluronic Acid Eye Drops
}

\author{
Ria Beck ${ }^{a}$ Oliver Stachs ${ }^{a} \quad$ Anita Koschmieder $^{a}$ \\ Wolfgang G.K. Mueller-Lierheim ${ }^{\mathrm{b}} \quad$ Sabine Peschel ${ }^{\mathrm{a}}$ \\ Gysbert-Botho van Setten ${ }^{c, d}$
}

aUniversity Eye Hospital, Rostock, Germany; bi.com medical GmbH, Munich, Germany; 'St Eriks Eye Hospital, Karolinska Institutet, Stockholm, Sweden; Institute of Wound Research and Department of Ophthalmology, University of Florida, Gainesville, FL, USA

\section{Keywords}

Dry eye $\cdot$ Autologous serum eye drops $\cdot$ Sjögren syndrome $\cdot$ Wound healing

\begin{abstract}
Introduction: Autologous serum eye drops (ASED) are used in the treatment of most severe stages of dry eye. Once introduced, it is currently considered impossible to return to other lubricating eye drops or other commercially available therapeutic regimen. Materials and Methods: In a randomized study, non-preserved high-molecular-weight hyaluronic acid eye drops were offered as an alternative to 11 patients using autologous serum treatment for at least 3 months. The control group $(n=5)$ continued their treatment with ASED. The verum group $(n=6)$ used very-high-molecular-weight hyaluronic eye drops (Comfort Shield ${ }^{\circledR}$ ) instead of the ASED. Results: From four of initially six patients in the verum group that finished the
\end{abstract}




\section{Case Reports in Ophthalmology}

Case Rep Ophthalmol 2019;10:244-255

DOI: $10.1159 / 000501712$

(c) 2019 The Author(s). Published by S. Karger AG, Base www.karger.com/cop

Beck et al.: Hyaluronic Acid as an Alternative to ASED

study, 2 (50\%) preferred to stay with the very-high-molecular-weight hyaluronic acid eye drops beyond the trial period, the other two returned to the earlier therapy with ASED. The control group continued their treatment as before and finished the study after 8 weeks. Conclusion: For the first time, artificial eye drops, i.e., high-molecular-weight hyaluronic acid eye drops, offered an acceptable alternative to ASED. Some patients perceived these drops as even better than the patient's own serum. This is the first evidence that optimization of the molecular structure of hyaluronic acid can be used to create eye drops that are perceived to be better than other tested tear substitutes and even patients' own serum. This offers a new treatment perspective for patients with very severe dry eye disease.

(C) 2019 The Author(s)

Published by S. Karger AG, Basel

\section{Introduction}

Autologous serum eye drops (ASED), a valuable alternative in the treatment of severe dry eye disease [1,2], are well tolerated and often preferred to tear fluid substitutes [3]. This is partly due to their surface-promoting and -reconstituting effects [4], which have become more predictable due to a fairly standardized production process [5-7]. Based on the concentration of biological factors in healthy tears [4], ASED are applied mainly in $20 \%$ serum concentration, although even higher concentrations (between 50 and 100\%) are in use [7-10]. Patients treated with $20 \%$ to $50 \%$ ASED four to eight times a day have reported subjective improvement in dry eye symptoms; investigators have also noted objective improvement in signs such as fluorescein staining and tear film break-up time (TBUT) [16-23]. The content of cytokines and other proteins that are also present in tears have made ASED a valuable treatment alternative [11]. Some cytokines such as epidermal growth factor have been found to occur in similar concentrations in healthy human tears and serum, whereas others have not, such as TGF$\beta[3,12,13]$. This observation contributed to the use of a diluted solution of serum to maintain TGF- $\beta$ levels that are comparable with those of tears. Variations in osmolarity of the autologous serum are balanced by the diluent balanced saline solution $[14,15]$. Serum eye drops are used in treatment of patients with several ocular surface disturbances such as Sjögren syndrome-related tear deficiency, tear deficiency associated with graft-versus-host disease, neurotrophic keratitis, persistent epithelial defects, superior limbic keratoconjunctivitis, and postoperative dry eye induced by LASIK. In all these conditions, investigators have reported objective improvements of clinical signs such as fluorescein staining and TBUT [16-24]. Being aware about these so far unmatched effects, we were interested in evaluating if the direct substitution of ASED with hyaluronate might be possible. To this issue, we have investigated this quest. Encouraged by initial results of an ongoing study with high-molecular-weight hyaluronic acid (Hyaluronan), we have, in a randomized trial, offered such eye drops as an alternative to patients on therapy with ASED and compared their efficacy with a control group of patients who remained on ASED therapy. 


\section{Case Reports in Ophthalmology}

Case Rep Ophthalmol 2019:10:244-255

DOI: $10.1159 / 000501712$

(c) 2019 The Author(s). Published by S. Karger AG, Base www.karger.com/cop

Beck et al.: Hyaluronic Acid as an Alternative to ASED

\section{Materials and Methods}

Eleven patients who had been on ASED treatment for at least 3 months gave their informed consent and were included in the study and randomized into two groups. In the verum group ( 6 patients), the ASED were substituted by high-molecular-weight hyaluronic acid eye drops for a period of 8 weeks, whereas the control group (5 patients) continued their ASED therapy (Table 1).

At three visits (i.e., baseline, after 4 weeks, after 8 weeks), the symptoms were assessed using the Ocular Surface Disease Index (OSDI) questionnaire [27]. The use of drops during the study (ad libitum) was recorded in case report forms.

\section{Autologous Serum Eye Drops}

Within the highly standardized preparation procedure for ASED at the Rostock University Eye Hospital, full blood samples were transferred into serum vials, left at room temperature for $20 \mathrm{~min}$, and after coagulation were centrifuged with $2,000 \mathrm{~g}$ at $10^{\circ} \mathrm{C}$ for $20 \mathrm{~min}$. Aliquots were created and diluted $1: 1$ by adding $0.9 \% \mathrm{NaCl}$ solution (balanced saline solution) and the vials were closed, mixed using a vortex mixer, and frozen at $-18^{\circ} \mathrm{C}$. The patients took their vials with frozen autologous serum home in a polystyrene box and kept them at $-18^{\circ} \mathrm{C}$. Only immediately before use did the patients defrost one vial and they stored the vial in use refrigerated at $2-8^{\circ} \mathrm{C}$.

\section{Hyaluronic Acid Eye Drops}

Non-preserved eye drops containing $0.15 \%$ very-high-molecular-weight hyaluronic acid (Comfort Shield ${ }^{\circledR}$, manufacturer: i.com medical GmbH, Munich, Germany) were used in this study. They contain only substances naturally occurring in the human eye.

\section{Diagnostics}

\section{Corneal Fluorescein Staining}

Preservative-free sodium fluorescein solution (Fluorescéine Faure $0.5 \%$ ophthalmic solution in $0.4 \mathrm{~mL}$ unit dose, SERB SAS, Paris, France) was applied. After blinking, 20-120 s after instillation, digital photos of the ocular surface were taken with a Canon EOS 5D camera (Canon Inc., Tokyo, Japan) connected to a Takagi SM-70N slit lamp (Takagi Seiko Co., Ltd., Nagano, Japan). Corneal fluorescein staining (CFS) grading was done according to the modified Oxford scale [28]. Additionally, the digital images were electronically transferred to the Reading Center at Freiburg University Eye Hospital for automated assessment of the staining. The images were binarized by means of adaptive thresholding and automated calculations resulting in a ratio considered to be equivalent to the percentage of the visible corneal area that is fluorescein stained. From this ratio, the automated Oxford grade of CFS was calculated [28].

\section{Additional Investigations}

Additional investigations included TBUT, where the average of three measurements was recorded, Schirmer I test without anesthesia (Mark Blu Schirmer Tear Test Ophthalmic Strips; OptiTech Europe BVBA, Antwerp, Belgium), and tear osmolarity using TearLab E-series osmolarity test system (TearLab Corporation, San Diego, CA, USA). In vivo confocal laser- 


\section{Case Reports in Ophthalmology}

Case Rep Ophthalmol 2019;10:244-255

DOI: $10.1159 / 000501712$

(c) 2019 The Author(s). Published by S. Karger AG, Basel www.karger.com/cop

Beck et al.: Hyaluronic Acid as an Alternative to ASED

scanning microscopy of the cornea was used as previously described $[29,30]$ using the Heidelberg Retina Tomograph (HRT II, Heidelberg Engineering GmbH, Heidelberg, Germany) in combination with the Rostock Cornea Module as described earlier [30]. The subjective symptoms of the patients were assessed at every visit using the OSDI questionnaire. Dropping frequency was also assessed: At the baseline visit, the patients were asked for the frequency of application of ASED. Throughout the study, the use of eye drops (hyaluronic acid eye drops or ASED) was recorded daily. Prior to the diagnostic procedures, the patients had not applied any eye drops for at least $1 \mathrm{~h}$.

\section{Statistics}

Due to the limited number of participating patients, any significance analysis was omitted and a descriptive analysis was performed comparing absolute numbers and mean values.

\section{Results}

Out of 11 patients initially included in the study, three (1 control, 2 verum group) were discontinued within the test period prior to the scheduled end of 8 weeks due to "no show," dementia, or timing issue. Eight patients (4 in each group) continued and followed the investigation as planned (Table 1). The symptoms as assessed by the OSDI score did - on average not significantly change over the 8-week trial period, nor did the average dropping frequency (Table 2). Two patients in the verum group experienced an improvement, whereas the other two felt a worsening of symptoms.

The OSDI scores of the patients in the verum and control group did not correlate with any of the diagnostic signs observed in the study. By the end of the study, the symptoms of 2 of the 4 verum patients (No. 1 and 4), i.e., 50\%, had improved. These patients decided to continue the use of high-molecular-weight hyaluronic acid eye drops instead of ASED. The symptoms of the other 2 patients (No. 2 and 3) got worse. These patients decided to return to the ASED therapy. In these patients, the offered treatment was found not to add any significant improvement for the patient.

The dropping frequency of the hyaluronic acid eye drops was only slightly different from the ASED dropping frequency by the time of inclusion of the patients. On both groups, there was a minor decrease in reported dropping frequency during the study (Table 2).

The results of CFS testing are provided in Table 3. As the condition of the ocular surface was severe, surface irregularities and alterations rendered some of the CFS unreliable. These were accordingly reported as ungradable.

Similarly, on the rough surfaces with irregularities, a reliable TBUT was often not measurable (Table 3). The Schirmer I test was slightly more successful and revealed some improvement in both groups, indicating only a minor difference between the groups, with slightly better values in the verum group (Table 3).

Osmolarity testing proved to be a real challenge in these patients as the tear meniscus in most patient eyes was minimal. Accordingly, in some patients, no sufficient volume could be retrieved and hence, the measurement was recorded as unmeasurable. Interestingly, however, in no patient, a osmolarity higher than $320 \mathrm{mosm} / \mathrm{L}$ was found and the difference between both eyes was minimal (Table 3). 


\section{Case Reports in Ophthalmology}

Case Rep Ophthalmol 2019;10:244-255

DOI: $10.1159 / 000501712$

(c) 2019 The Author(s). Published by S. Karger AG, Basel www.karger.com/cop

Beck et al.: Hyaluronic Acid as an Alternative to ASED

By the time of inclusion in the study, the subbasal nerve plexuses of the patients investigated by confocal laser-scanning microscopy were very heterogenous. There were significant differences from patient to patient from almost no to reasonable innervation. There were well-defined subbasal nerves in the verum group (see Fig. 1) as well as in the control group. No major differences between innervation and appearance of the subbasal nerve plexus at baseline and after 8 weeks could be observed. In general, the appearance of the cornea at the level of the subbasal nerve plexus looked extremely heterogenic in both verum and control group. These differences did not correlate with other signs and symptoms. Moreover, these differences did not have any predictive value for the decision of the patient to continue or discontinue with high-molecular-weight hyaluronic acid eye drops, even after the end of the study.

\section{Discussion}

This is, to the best of our knowledge, the first report giving evidence that artificial eye drops are preferred by patients to products derived form their own blood, so far considered the last level of advanced treatment of most severe dry eye disease. In the current study, we could show that very-high-molecular-weight hyaluronic acid eye drops are perceived as a preferred alternative to ASED by some patients. This study outlines that hyaluronic acid alone, when presented to the diseased ocular surface in an optimal galenic formulation, in the right concentration, and with a molecular size of hyaluronic acid close to the natural hyaluronic acid occurring at the surface, is a possible alternative to the use of ASED for some patients. The authors are not aware of any report so far suggesting that the last resort of severe dry eye treatment, i.e., therapy with serum eye drops, could be successfully replaced by synthetic tear substitute eye drops. In our study, we could show that over a period of 8 weeks, 4 out of 6 patients who had been under ASED treatment for a long time could be switched to the treatment with high-molecular-weight hyaluronic acid eye drops without significant change of signs of ocular surface disease, and that 2 of these patients even experienced an improvement of symptoms as determined by the OSDI. On the other hand, 2 out of 4 patients opted for returning to the ASED treatment after trying the alternative regimen for 8 weeks. Possibly, for those patients, a combination of hyaluronic acid and serum eye drops could lead to a combination of beneficial effects by a gradual, slow release of growth factors over a prolonged period of time, resulting in a beneficial effect on the ocular surface, as a recently published study suggests [31]. Here again, ASED had to be used from the refrigerator. Interestingly, however, in such combination, the use of high-molecular-weight hyaluronic acid could promote the anti-inflammatory effect of serum eye drops, as reported by Stenwall and colleagues [11].

The use of very-high-molecular-weight hyaluronic acid eye drops as a replacement for ASED has practical aspects. Not only would it serve as temporary supplement or replacement for serum eye drops, it could also serve as initial substitute to serum eye drops when regulatory or cultural issues prohibit the access to serum eye drops or only allogeneic serum eye drops could be offered. Moreover, very-high-molecular-weight hyaluronic acid eye drops are not derived from blood and hence, do not carry the risk of infection. They do not require particular transport and storage like cooling/freezing and are less costly. 


\section{Case Reports in Ophthalmology}

Case Rep Ophthalmol 2019;10:244-255

DOI: $10.1159 / 000501712$

(c) 2019 The Author(s). Published by S. Karger AG, Basel www.karger.com/cop

Beck et al.: Hyaluronic Acid as an Alternative to ASED

This study emphasizes the importance not only of the very-high-molecular-weight hyaluronic acid contained in Comfort Shield ${ }^{\circledR}$ eye drops and its concentration, mimicking the rheology of healthy human tears, but of the entire galenic formulation. This study also supports the increasing evidence that osmolarity is not a suitable diagnostic tool in severe/very severe dry eye disease as we did not find a significant hyperosmolarity in any measurement (maximum value $320 \mathrm{mosm} / \mathrm{L}$ ). This finding is in line with a previous report showing that tear osmolarity was not statistically different between healthy subjects (306 mosm/L) and patients with dry eye disease (302 and 301 mosm/L before and after treatment with serum eye drops, respectively) [32]. The application of isotonic eye drops to a normo-osmolar ocular surface avoids any provoked osmotic stress by fluctuations in osmolarity to injured and chronically inflamed ocular surfaces. This is a particularly relevant finding as hyperosmolarity $(>308$ mosm/L) has been outlined as the key causal factor in the pathophysiology of severely dry eye and the causative factor in the vicious circle of dry eye disease [33, 34]. Future and ongoing studies will provide further evidence on this important aspect.

In the present study, all other signs of dry eye investigated (Schirmer test, TBUT, etc.) did not show any significant difference between the verum and control group. Furthermore, this study showed that in very severe dry eye disease, the condition of the surface may not allow the reliable use of an ocular surface staining score. Similar to these difficulties in the diagnostics of severe dry eye disease, confocal microscopy of the sub-basal nerve plexus did not provide any indication whether or not an individual patient would accept substitution of ASED by high-molecular-weight hyaluronic acid eye drops.

When using ASED in the treatment of severe ocular surface disease, we should be aware that the serum composition of multi-morbid patients may be seriously affected by the general health of the individual patient. Although rather standardized in concentration and production, its composition is dependent on the blood composition, which is affected by the actual general health condition of the body [3]. In general, the concentration of various components is higher in the tear film than in serum, whereas others such as vitamin A is substantially higher in serum [35-37]. Serum lipid profiles are significantly altered in systemic disease such as connective tissue diseases [38]. Cardiovascular disease may reflect in altered levels of plasminogen activator [39]. Additionally, concentrations of VEGF and IL-6 were increased in patients with rheumatoid arthritis [40]. IL-1 $\beta$ and TNF $\alpha$ levels are elevated in the peripheral blood of patients with primary Sjögren syndrome [41]. Taking this into account, as well as the effect that the alterations vary with the intensity of the disease, i.e., also during the treatment, it becomes evident that the presence of quality and quantity of various factors in the serum may vary. This also implies a variation in efficacy and tolerability of ASED in the most severely affected eyes. It is not unlikely that the serum of patients with highest general disease activity might have deficient and potentially harmful composition. It is here that the high-molecularweight hyaluronan eye drops offer a great advantage due to their reproducible composition and absence of potentially harmful substances. It is likely that high-molecular-weight hyaluronan eye drops offer significant advantages particularly for the treatment of severe dry eye in patients with severe systemic disease. Additionally, severe systemic disease seldom matches the option for frequent and repeated blood sampling.

High-molecular-weight hyaluronan eye drops used in this study represent a so far unmet potential tool and, at least temporarily, an effective alternative to ASED. All the more so as there are patient groups that do not respond so well to serum eye drops. According to Hwang 


\section{Case Reports in Ophthalmology}

et al. [42], ASED might not be effective for the treatment of secondary Sjögren syndrome because of elevated serum proinflammatory cytokine levels. In such patients, the use of highmolecular-weight hyaluronan eye drops could offer a valuable alternative. However, as by today, there is a lack of specific guidelines that help to identify patients where the access to ASED due to systemic disease is either limited or where the quality of ASED, due to the nature of the underlying systemic disease, is suboptimal. It is these conditions that would favor the use of high-molecular-weight hyaluronan eye drops.

\section{Conclusion}

High-molecular-weight hyaluronic acid eye drops have unique features that resemble the natural hyaluronic acid at the ocular surface so much that apparently in some patients, these drops are perceived to be even better than the patient's own serum. The study clearly indicates that the molecular structure and size of the hyaluronic acid molecule has clinical relevance. This is the first evidence that optimization of the molecular structure of the hyaluronic acid molecule could lead to eye drops that resemble natural tears to a yet unmet extent. The results and their interpretation are limited because of the limited number of cases. In order to support the initial results presented herein, further prospective studies with a larger number of patients and, possibly, a switch-over design would be needed.

\section{Acknowledgments}

The significant support of Professor Dr. med. Daniel Böhringer, University Eye Hospital Freiburg, Germany, in the development and application of the methods used is highly appreciated and acknowledged. The authors are very thankful to the Foundation of the Visually Impaired (Synfrämjandets Forskningsfond, SFF), Stockholm, Sweden for granting time for this study. Aviation-Ophthalmology, Inc., Sweden is thankfully acknowledged for providing knowhow, technical help, and assistance.

\section{Statement of Ethics}

The study, approved by the local Ethics Committee and by the German Bundesinstitut für Arzneimittel und Medizinprodukte (BfArM), is in accordance with EN ISO 14155 [25] and the Declaration of Helsinki, and is registered with the EUDAMED registration number CIV-16-06015964. The study was sponsored and monitored by CORONIS GmbH (Munich, Germany), an organization with a quality management system for clinical research, certified and annually audited in accordance to the international standard EN ISO 13485 by a European Notified Body [26]. 


\section{Disclosure Statement}

Ria Beck and Gysbert van Setten have no financial interest in this publication. Dr. Wolfgang Mueller-Lierheim shares interest as sponsor of the study in his position as CEO of I-Com medical GmbH, Munich Germany.

\section{Funding Sources}

I-Com medical GmbH, Munich, Germany.

\section{References}

1 Fox RI, Chan R, Michelson JB, Belmont JB, Michelson PE. Beneficial effect of artificial tears made with autologous serum in patients with keratoconjunctivitis sicca. Arthritis Rheum. 1984 Apr;27(4):459-61.

2 Giannaccare G, Versura P, Buzzi M, Primavera L, Pellegrini M, Campos EC. Blood derived eye drops for the treatment of cornea and ocular surface diseases. Transfus Apheresis Sci. 2017 Aug;56(4):595-604.

3 Pan Q, Angelina A, Marrone M, Stark WJ, Akpek EK. Autologous serum eye drops for dry eye. Cochrane Database Syst Rev. 2017 Feb;2:CD009327.

4 Young AL, Cheng AC, Ng HK, Cheng LL, Leung GY, Lam DS. The use of autologous serum tears in persistent corneal epithelial defects. Eye (Lond). 2004 Jun;18(6):609-14.

5 Geerling G, Unterlauft JD, Kasper K, Schrader S, Opitz A, Hartwig D. [Autologous serum and alternative blood products for the treatment of ocular surface disorders]. Ophthalmologe. 2008 Jul;105(7):623-31.

6 Liu L, Hartwig D, Harloff S, Herminghaus P, Wedel T, Geerling G. An optimised protocol for the production of autologous serum eyedrops. Graefes Arch Clin Exp Ophthalmol. 2005 Jul;243(7):706-14.

7 Geerling G, Maclennan S, Hartwig D. Autologous serum eye drops for ocular surface disorders. $\mathrm{Br}$ ] Ophthalmol. 2004 Nov;88(11):1467-74.

8 Dogru M, Tsubota K. Pharmacotherapy of dry eye. Expert Opin Pharmacother. 2011 Feb;12(3):325-34.

9 Kojima T, Ishida R, Dogru M, Goto E, Matsumoto Y, Kaido M, et al. The effect of autologous serum eyedrops in the treatment of severe dry eye disease: a prospective randomized case-control study. Am J Ophthalmol. 2005 Feb;139(2):242-6.

10 Quinto GG, Campos M, Behrens A. Autologous serum for ocular surface diseases. Arq Bras Oftalmol. 2008 Nov-Dec;71(6 Suppl):47-54.

11 Stenwall PA, Bergström M, Seiron P, Sellberg F, Olsson T, Knutson F, et al. Improving the anti-inflammatory effect of serum eye drops using allogeneic serum permissive for regulatory $\mathrm{T}$ cell induction. Acta Ophthalmol. 2015 Nov;93(7):654-7.

12 Tsubota K, Higuchi A. Serum application for the treatment of ocular surface disorders. Int Ophthalmol Clin. 2000;40(4):113-22.

13 van Setten GB, Tervo T, Viinikka L, Pesonen K, Perheentupa J, Tarkkanen A. Ocular disease leads to decreased concentrations of epidermal growth factor in the tear fluid. Curr Eye Res. 1991 Jun;10(6):523-7.

14 Tsubota K, Yamada M. Tear evaporation from the ocular surface. Invest Ophthalmol Vis Sci. 1992 Sep;33(10):2942-50.

15 Siervo M, Bunn D, Prado CM, Hooper L. Accuracy of prediction equations for serum osmolarity in frail older people with and without diabetes. Am J Clin Nutr. 2014 Sep;100(3):867-76.

16 Ferreira de Souza R, Kruse FE, Seitz B. [Autologous serum for otherwise therapy resistant corneal epithelial defects - Prospective report on the first 70 eyes]. Klin Monatsbl Augenheilkd. 2001 Nov;218(11):720-6.

17 Chiang CC, Lin JM, Chen WL, Tsai YY. Allogeneic serum eye drops for the treatment of severe dry eye in patients with chronic graft-versus-host disease. Cornea. 2007 Aug;26(7):861-3.

18 Hyon JY, Lee YJ, Yun PY. Management of ocular surface inflammation in Sjögren syndrome. Cornea. 2007 Oct;26(9 Suppl 1):S13-5.

19 Kojima T, Higuchi A, Goto E, Matsumoto Y, Dogru M, Tsubota K. Autologous serum eye drops for the treatment of dry eye diseases. Cornea. 2008 Sep;27 Suppl 1:S25-30. 
20 Matsumoto Y, Dogru M, Goto E, Ohashi Y, Kojima T, Ishida R, et al. Autologous serum application in the treatment of neurotrophic keratopathy. Ophthalmology. 2004 Jun;111(6):1115-20.

21 Ogawa Y, Okamoto S, Mori T, Yamada M, Mashima Y, Watanabe R, et al. Autologous serum eye drops for the treatment of severe dry eye in patients with chronic graft-versus-host disease. Bone Marrow Transplant. 2003 Apr;31(7):579-83.

22 Tananuvat N, Daniell M, Sullivan LJ, Yi Q, McKelvie P, McCarty DJ, et al. Controlled study of the use of autologous serum in dry eye patients. Cornea. 2001 Nov;20(8):802-6.

23 Poon AC, Geerling G, Dart JK, Fraenkel GE, Daniels JT. Autologous serum eyedrops for dry eyes and epithelial defects: clinical and in vitro toxicity studies. Br J Ophthalmol. 2001 Oct;85(10):1188-97.

24 Tsubota K, Goto E, Fujita H, Ono M, Inoue H, Saito I, et al. Treatment of dry eye by autologous serum application in Sjögren's syndrome. Br J Ophthalmol. 1999 Apr;83(4):390-5.

25 EN ISO 14155:2011 Clinical investigation of medical devices for human use - Good clinical practice (ISO 14155:2011), 2011.

26 EN ISO 13485:2012 (ISO 13485:2003), Medical devices - Quality management systems - Requirements for regulatory purposes, 2012.

27 Schiffman RM, Christianson MD, Jacobsen G, Hirsch JD, Reis BL. Reliability and validity of the Ocular Surface Disease Index. Arch Ophthalmol. 2000 May;118(5):615-21.

28 Bron AJ, Evans VE, Smith JA. Grading of corneal and conjunctival staining in the context of other dry eye tests. Cornea. 2003 Oct;22(7):640-50.

29 Guthoff RF, Zhivov A, Stachs O. In vivo confocal microscopy, an inner vision of the cornea - a major review. Clin Exp Ophthalmol. 2009 Jan;37(1):100-17.

30 Ziegler D, Papanas N, Zhivov A, Allgeier S, Winter K, Ziegler I, et al.; German Diabetes Study (GDS) Group. Early detection of nerve fiber loss by corneal confocal microscopy and skin biopsy in recently diagnosed type 2 diabetes. Diabetes. 2014 Jul;63(7):2454-63.

31 López-García JS, García-Lozano I, Rivas L, Ramírez N, Raposo R, Méndez MT. Autologous serum eye drops diluted with sodium hyaluronate: clinical and experimental comparative study. Acta Ophthalmol. 2014 Feb;92(1):e22-9.

32 Mahelková G, Veselá V, Seidler Štangová P, Židlická A, Dotřelová D, Fales I, et al. [Tear Osmolarity in Patients with Severe Dry Eye Syndrome Before and After Autologous Serum Treatment: a Comparison with Tear Osmolarity in Healthy Volunteers]. Cesk Slov Oftalmol. 2015 Aug;71(4):184-8.

33 Craig JP, Nichols KK, Akpek EK, Caffery B, Dua HS, Joo CK, et al. TFOS DEWS II Definition and Classification Report. Ocul Surf. 2017 Jul;15(3):276-83.

34 Baudouin C. The pathology of dry eye. Surv Ophthalmol. 2001 Mar;45 Suppl 2:S211-20.

35 Ubels JL, MacRae SM. Vitamin A is present as retinol in the tears of humans and rabbits. Curr Eye Res. 1984 Jun;3(6):815-22.

36 Tsubota K, Goto E, Shimmura S, Shimazaki J. Treatment of persistent corneal epithelial defect by autologous serum application. Ophthalmology. 1999 Oct;106(10):1984-9.

37 Khaksari M, Mazzoleni LR, Ruan C, Kennedy RT, Minerick AR. Determination of water-soluble and fat-soluble vitamins in tears and blood serum of infants and parents by liquid chromatography/mass spectrometry. Exp Eye Res. 2017 Feb;155:54-63.

38 Rössner S. Further studies on serum lipoproteins in connective tissue diseases. Atherosclerosis. 1978 Sep;31(1):93-9.

39 Hamsten A, de Faire U, Walldius G, Dahlén G, Szamosi A, Landou C, et al. Plasminogen activator inhibitor in plasma: risk factor for recurrent myocardial infarction. Lancet. 1987 Jul;2(8549):3-9.

40 Oranskiy SP, Yeliseyeva LN, Tsanaeva AV, Zaytseva NV. Body composition and serum levels of adiponectin, vascular endothelial growth factor, and interleukin-6 in patients with rheumatoid arthritis. Croat Med J. 2012 Aug;53(4):350-6.

41 Willeke P, Schotte H, Schlüter B, Erren M, Becker H, Dyong A, et al. Interleukin 1beta and tumour necrosis factor alpha secreting cells are increased in the peripheral blood of patients with primary Sjögren's syndrome. Ann Rheum Dis. 2003 Apr;62(4):359-62.

42 Hwang J, Chung SH, Jeon S, Kwok SK, Park SH, Kim MS. Comparison of clinical efficacies of autologous serum eye drops in patients with primary and secondary Sjögren syndrome. Cornea. 2014 Jul;33(7):663-7. 


\section{Case Reports in Ophthalmology}
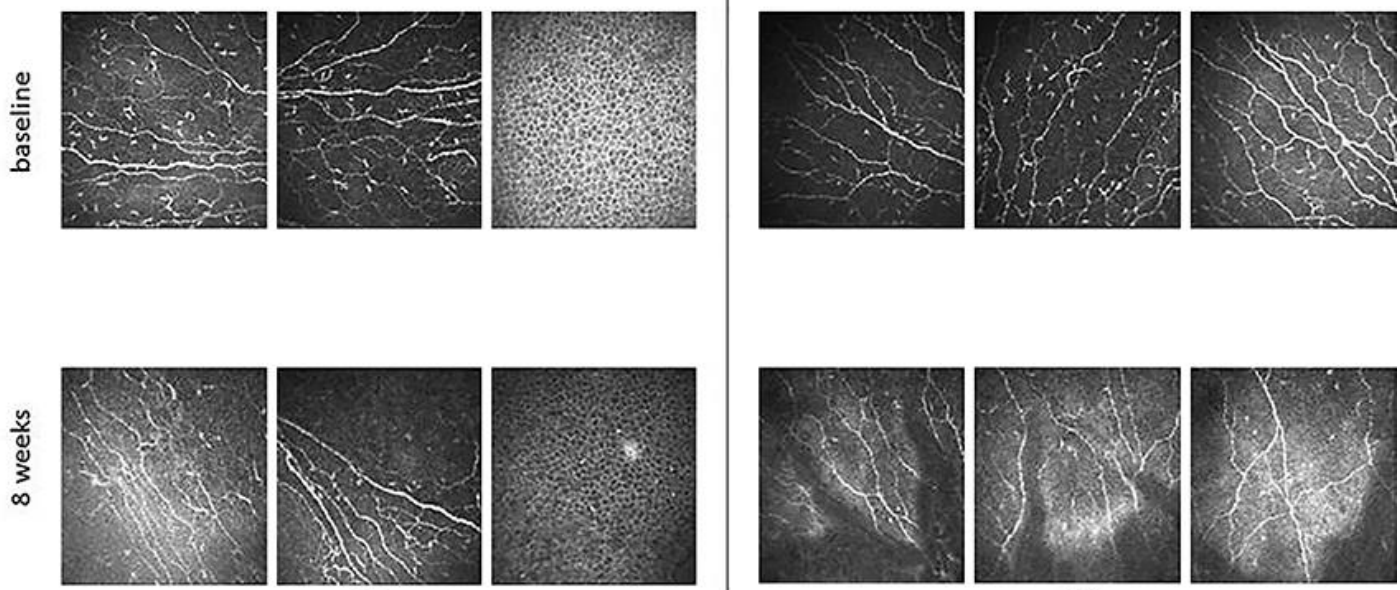

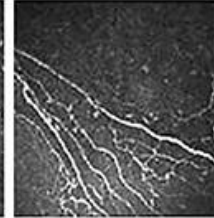

OS

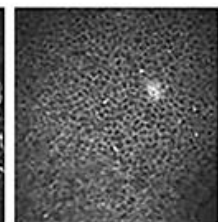

3.
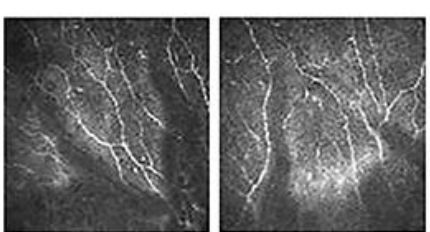

$O D$

Fig. 1. Picture from corneal nerves in a patient from the verum group staying on hyaluronic acid eye drops even after the study.

Table 1. Patient history and descriptive data of the verum and control group

\begin{tabular}{|c|c|c|c|c|c|}
\hline Patient & $\begin{array}{l}\text { Drop- } \\
\text { out }\end{array}$ & $\begin{array}{l}\text { Age, } \\
\text { years }\end{array}$ & Gender & & $\begin{array}{l}\text { Duration } \\
\text { of ASED } \\
\text { treatment, } \\
\text { months }\end{array}$ \\
\hline \multicolumn{6}{|c|}{ Verum group } \\
\hline 1 & & 79 & Male & Keratitis filiformis & 45 \\
\hline 2 & & 76 & Male & Allergic conjunctivitis: diabetes; adipohepatic & 16 \\
\hline & $\mathrm{X}$ & 32 & Male & Acute lymphatic leukemia; stem cell transplantation & 82 \\
\hline 3 & & 80 & Female & Neuropathic keratopathy; herpes zoster OD; corneal ulcus; cataract & 43 \\
\hline & $\mathrm{X}$ & 59 & Female & Acute lymphatic leukemia; stem cell transplantation & 20 \\
\hline 4 & & 67 & Female & Sjögren syndrome & 50 \\
\hline \multicolumn{6}{|c|}{ Control group } \\
\hline 5 & & 72 & Female & Keratoconjunctivitis sicca; ptosis and incomplete lid closure OD & 6 \\
\hline & $\mathrm{X}$ & 88 & Female & Keratoconjunctivitis sicca & 39 \\
\hline 6 & & 67 & Female & Sjögren syndrome; n. opticus atrophy OD & 39 \\
\hline 7 & & 82 & Female & Keratoconjunctivitis sicca; burning sensation; rheumatoid arthritis & 13 \\
\hline 8 & & 59 & Female & GVHD with myelodysplastic syndrome; stem cell therapy & 10 \\
\hline
\end{tabular}




\section{Case Reports in Ophthalmology}

\begin{tabular}{l|l}
\hline Case Rep Ophthalmol 2019;10:244-255 \\
\hline DOl: 10.1159/000501712 & $\begin{array}{l}\text { @ } 2019 \text { The Author(s). Published by S. Karger AG, Basel } \\
\text { www.karger.com/cop }\end{array}$ \\
\hline
\end{tabular}

Beck et al.: Hyaluronic Acid as an Alternative to ASED

Table 2. OSDI scores and dropping frequency of verum and control group

\begin{tabular}{lccc}
\hline Patient & Baseline & 4 weeks & 8 weeks \\
\hline OSDI verum & & & \\
1 & 71.9 & 44.4 & 41.7 \\
2 & 43.8 & 61.1 & 60.0 \\
3 & 65.6 & 67.5 & 72.5 \\
4 & 68.8 & 75.0 & 63.6 \\
Mean & 62.5 & 62.0 & 59.5 \\
\hline Dropping frequency verum & & & \\
1 & $14 /$ day & $13 /$ day & $13 /$ day \\
2 & $14 /$ day & $8 /$ day & $10 /$ day \\
3 & $6 /$ day & $10 /$ day & $8 /$ day \\
4 & $14 /$ day & $18 /$ day & $14 /$ day \\
Mean & 12 & 12 & 11 \\
\hline OSDI control & & & \\
5 & 50.0 & 45.5 & 45.8 \\
6 & 52.3 & 47.7 & 50.0 \\
7 & 66.7 & 58.3 & 75.0 \\
8 & 42.5 & 62.5 & 57.5 \\
Mean & 52.9 & 53.5 & 57.1 \\
\hline Dropping frequency control & \multicolumn{3}{c}{} \\
5 & $14 /$ day & $5 /$ day & $5 /$ day \\
6 & $28 /$ day & $11 /$ day & $11 /$ day \\
7 & $14 /$ day & $7.5 /$ day & $7 /$ day \\
8 & $7 /$ day & $14 /$ day & $15 /$ day \\
Mean & 16 & 9.5 & 9.5 \\
\hline & \multicolumn{3}{c}{} \\
\hline
\end{tabular}


Beck et al.: Hyaluronic Acid as an Alternative to ASED

Table 3. CFS, TBUT, Schirmer I test, and osmolarity of the verum and control group

\begin{tabular}{|c|c|c|c|c|c|c|c|}
\hline & \multirow[t]{2}{*}{ Patient } & \multicolumn{3}{|l|}{ Right eye } & \multicolumn{3}{|l|}{ Left eye } \\
\hline & & Baseline & 4 weeks & 8 weeks & Baseline & 4 weeks & 8 weeks \\
\hline \multicolumn{8}{|c|}{ CFS test (Oxford scale) } \\
\hline \multirow[t]{4}{*}{ Verum } & 1 & III & IV & IV & I & IV & IV \\
\hline & 2 & $\mathrm{u}$ & $\mathrm{u}$ & $\mathrm{u}$ & III & $\mathrm{u}$ & $\mathrm{u}$ \\
\hline & 3 & IV & IV & $\mathrm{u}$ & III & IV & $\mathrm{u}$ \\
\hline & 4 & III & IV & III & I & III & I \\
\hline \multirow[t]{4}{*}{ Control } & 5 & $\mathrm{u}$ & IV & $\mathrm{u}$ & 0 & 0 & $\mathrm{u}$ \\
\hline & 6 & III & I & IV & IV & II & IV \\
\hline & 7 & 0 & I & I & 0 & I & $\mathrm{I}$ \\
\hline & 8 & IV & IV & $\mathrm{u}$ & IV & $\mathrm{u}$ & $\mathrm{u}$ \\
\hline \multicolumn{8}{|c|}{ TBUT test, $s$} \\
\hline \multirow[t]{4}{*}{ Verum } & 1 & 3 & nd & 2 & 3 & nd & 1 \\
\hline & 2 & 2 & 2 & 4 & 4 & 3 & 4 \\
\hline & 3 & 2 & 2 & 3 & 1 & 1 & 3 \\
\hline & 4 & 2 & 11 & 4 & 2 & 9 & 4 \\
\hline \multirow[t]{4}{*}{ Control } & 5 & 2 & 2 & 4 & 3 & 3 & 8 \\
\hline & 6 & 5 & 4 & 3 & 4 & 4 & 4 \\
\hline & 7 & 1 & 6 & nd & 1 & 12 & nd \\
\hline & 8 & 3 & 2 & 2 & 3 & 1 & 2 \\
\hline \multicolumn{8}{|c|}{ Schirmer I test, $\mathrm{mm} / 5 \mathrm{~min}$} \\
\hline \multirow[t]{4}{*}{ Verum } & 1 & 1 & & 12 & 1 & & 17 \\
\hline & 2 & 1 & & 5 & 4 & & 9 \\
\hline & 3 & 0 & & 2 & 1 & & 0 \\
\hline & 4 & 5 & & 5 & 3 & & 6 \\
\hline \multirow[t]{4}{*}{ Control } & 5 & 0 & & 2 & 0 & & 0 \\
\hline & 6 & 1 & & 0 & 0 & & 0 \\
\hline & 7 & 1 & & 11 & 1 & & 14 \\
\hline & 8 & 0 & & 5 & 0 & & 7 \\
\hline \multicolumn{8}{|c|}{ Osmolarity, mosm/L } \\
\hline \multirow[t]{4}{*}{ Verum } & 1 & 291 & & 293 & 293 & & 286 \\
\hline & 2 & 287 & & 302 & 282 & & 290 \\
\hline & 3 & $\mathrm{u}$ & & 315 & 306 & & 311 \\
\hline & 4 & $\mathrm{u}$ & & 283 & $\mathrm{u}$ & & $<280$ \\
\hline \multirow[t]{4}{*}{ Control } & 5 & 300 & & $\mathrm{u}$ & 312 & & 306 \\
\hline & 6 & 308 & & 307 & 309 & & 302 \\
\hline & 7 & 318 & & $\mathrm{u}$ & 320 & & 306 \\
\hline & 8 & 284 & & 301 & $\mathrm{u}$ & & 295 \\
\hline
\end{tabular}

u, ungradable; nd, not determined. 